\title{
MATH AND ART CONVERGENCE FOR EDUCATION
}

\section{Michela Tramonti, ${ }^{1}$ Desislava Paneva-Marinova, ${ }^{2}$ Radoslav Pavlov ${ }^{3}$}

\begin{abstract}
According to worldwide surveys (such as PISA and TIMSS), European students often lack both mathematical and key basic competencies in science and technology. The mean scores for mathematics obtained by students are below the Organisation for Economic Co-operation and Development average (OECD). The learning of the mathematics literacy enables students to contribute effectively in actual society, enhancing their employment prospects. This paper intends to describe an innovative learning and teaching approach, actually in the development phase, in the field of mathematics for 1416 years old students through the combination of current approaches used in Europe (such as inquiry based learning and technology-enhanced learning) and the Asian one, the Singapore's method based on three phases, concrete-pictorial-abstract, through the use of artworks. This intends to allow the development of a more effective educational and training environment for teachers and their students who will benefit from the use of more attractive and fun pedagogical tools in the study of mathematics.
\end{abstract}

UDC Classification: 373, 37.02, 7.063; DOI: http://dx.doi.org/10.12955/cbup.v5.1037

Keywords: mathematics education, learning by doing, inquiry-based learning, arts, technology-enhanced learning

\section{Introduction}

The globalized labor world market requires knowledge based on solid basic skills such as literacy in mathematics. For the development of math skills, teaching strategies and practices become primary for educational growth during all the school years. Taking into account the "Mathematics, Science \& Technology Education Report" (ERT, 2009), where education has been acknowledged as the cornerstone of Europe's success and will continue to be a determining factor in the prosperity of Europe's citizens and economy for the foreseeable future, competency in mathematics, science and technology is becoming more and more fundamental. For Europe as a whole, mathematics, science, and technology education plays a key role in adequately growing the research and development capacity, and ensuring economic and productivity growth that are crucial to Europe's future competitive position. The learning of the mathematics and science literacy enables students to contribute effectively in actual society, improving their employment prospects.

New strategies for mathematics teaching and learning and the deployment of workable learning methods for a better understanding and creative thinking are required for the engagement of learners in more active participation during the perceiving of knowledge.

This paper presents a research model and a technology-oriented solution that could provide a capstone experience in which students synthesize exact precise math principles with arts. Our research aims to investigate and analyse how the combination between meaningful learning and mastery learning produces an increase of motivation and interest for the study of mathematics as to obtain a meaningful improvement in students' final performances. In addition, since European students often lack mathematical and key basic competencies in science and technology, while the Asian students achieve the highest place in the ranking (OECD, 2014) (Mullis et al. 2012), we also exploit the combination between European teaching approach such as inquiry based learning and the potentialities of Singapore's method, used in some Asian countries, to improve the performances in math learning. This will allow students to improve and develop their learning skills with a creative and innovative study through an appropriate development of creativity-based approach in learning and problemsolving skills.

\section{Math and Art Convergence}

The human body and the related dimensional proportionality have always been among the basic cornerstonesin the history of fine arts (Gombrich, 2006). But, in order to be more realistic, they had to also devote themselves to the in-depth studies of geometry, anatomy, and architecture. One of the best

\footnotetext{
${ }^{1}$ Michela Tramonti, PhD student, Institute of Mathematics and Informatics, Bulgarian Academy of Sciences, Sofia, Bulgaria, tramonti.michela@gmail.com

${ }^{2}$ Assoc. Prof. Desislava Paneva-Marinova, PhD, Institute of Mathematics and Informatics, Bulgarian Academy of Sciences, Sofia, Bulgaria, dessi@cc.bas.bg

${ }^{3}$ Prof. Radoslav Pavlov, PhD, Institute of Mathematics and Informatics, Bulgarian Academy of Sciences, Sofia, Bulgaria, radko@cc.bas.bg
} 
known artists who used mathematics was the outstanding artist Mauritius Cornelis Escher (18981972). In arts, we find other examples such as the perspective in painting, the harmonic series in music (Fibonacci numbers), the physics principles in dancing (the symmetry of the body that allows to find the so-called "center of gravity" and so to maintain stability (Maletic, 1987)), etc. In addition, there are numerous examples of art that have evidence of the relation between math and popular culture as well:

- math in popular movies (imaginary travel through the collections of video clips, where math issues are involved);

- math and music (games, where are learning math concepts like patterns, shapes and comparative sizes through guided play as performers);

- math and textile arts (collections of puzzles).

Moreover, there are recent studies on the role of arts in promoting innovations in science (Lamb, 2012; Schwartz, 2015), and the chances to identify "exceptional talent" in children, which shall enable their success in the research and innovation field in future. Amongst such exceptional talents are mathematic ability, imagination, and music.

In this context, the use of art in the framework of the proposed research model will let students discover how mathematics and scientific roles have an impact on all aspects of the reality by showing that arts provide innovations through analogies, models, skills, structures, techniques, methods, and knowledge. Laboratories developed in this research aim to provide a virtual space for discovering and enhancing such talents among young people.

Thus, the research aims to test a combination of European and Asian (Singapore's method) learning methods and teaching approaches in the field of mathematics through the arts' and the application of technology as described in the paragraph below.

\section{Didactic framework}

The model proposed in this research work is the result of the integration of the three types of didactical situations identified by Brousseau (2002). Therefore, the learning/teaching situation developed according to the three phases of Singapore's method applied to the mathematics learning and teaching - concrete, pictorial and abstract phases (Gu et al., 2004; Clements, 1999), will be Adidactical, Non-didactical, Didactical.

In detail, the designed learning environment will be:

- A-didactical, because the students will learn mathematical topics by discovering that different relationships exist among things or math concepts (even if they cannot be so explicit) and by developing, accordingly, problem solving skills yet avoiding just memorizing the solution procedure.

- Didactical, because several worksheets will be prepared for the students before starting the experimentation phase. These will contain instructions to lead the student from the concrete phase to the pictorial, and up to the abstract one.

- Non-didactical, because the teacher will have the function to mediate and support the learning process through the creativity and the imagination of their students. The use of the creativity from students will be free, especially when they will produce their own artworks on the basis of the math concepts studied.

Therefore, considering the Didactics Hexagon proposed by Guy Brousseau (Brousseau, 2002) from the proposed model point of view, the art will be identified as the "context" or better the "milieu" to be used to reach knowledge. Knowledge achieved by students will be "constructed," implying that students will go systematically through the concrete phase to pictorial up to reach the abstract of a math concept.

This will allow students to reinforce their mathematics knowledge using the specific artworks to develop systems thinking based on applicable knowledge, imagination, creativity and problem-solving skills by facing math problem with variations. This last element is used systematically in Chinese mathematics teaching and it means that even if the mathematics formula/concept to be studied remains constant, the background/the contest or, adopting Brousseau's term, milieu, referring to them can be 
different. In our specific research the artwork, as milieu, represents a changeable context in which the students will gain an approach and learn in depth mathematical concepts.

Specifically, on the base of the Singapore's method, students will proceed through the three phases as described below.

Firstly, during the concrete phase of the proposed method, students will learn and familiarize themselves with the specific objects' construction, e.g. a dodecahedron. Secondly, students will learn to recognize mathematics in the art, working in groups and individually during the pictorial phase. Finally, they will create their artwork starting from the math formula studied.

Moreover, in order to reinforce the learning process during the phases, the technology of modeling programs will be used for objects and the creation of 3D virtual environments (Zheleva \& Tramonti, 2015). For this aim, one of the possible technical solutions could be the virtual platform "Math Art Café."

\section{Virtual Platform "Math Art Café"}

The platform "Math Art Cafe"" is an example of the virtual environment integrating art and science learning used mainly a communication tool for learning, practicing, and sharing of experiences (Senka, et al., 2016). The platform "Math Art Cafe"" will cover the following virtual components:

- Lab Gates - this area will provide entrances to the virtual laboratory. In these immersive spaces participants acting via their avatars will be able to:

a. Create different art performances using their Mathematics and Science knowledge and skills;

b. Present their works of art to the other 2D/3D world inhabitancies - exhibitions, theatres, concerts, and other stage performances;

c. Receive feedback from the audience by means of textual instant messages (group messages or private ones), voice communications, and non-verbal communications (applauses, avatars' mimics and gestures, etc.).

- Application Pool - all registered users will be able to publish documents, applications and/or links for downloading applications, which they consider interesting, useful, and cheerful. In this area, the platform users will be able to vote, comment, and evaluate all the published materials;

- Meeting point - a place where users will be able to meet each other, to exchange contact information, and to form groups of interests;

- Agora - a place where users will be able to exchange ideas and opinions concerning the thematic areas of common interest.

The "Math Art Cafe"" will have a wide range of users: teachers and students, artists and scientists, involved in arts and science integration activities, and facilitators such as education planners, public authorities, etc. The target community will have an interest in innovative arts and science representation. The platform is oriented to scientists, artists and teachers leading similar learning projects or have experience in such projects. Learning-by-authoring and doing are base learning methods in this research. The digital art content in the "Math Art Café" will be delivered by the ecosystems for digital cultural assets, digital collections, archives, virtual museums, digital libraries, cultural heritage sites, etc.

The "Math Art Cafe" platform is in a stage of design and technological development. Applications will be managed as an open source platform, which means, that all references and training/workshop materials will be available to its users for free. No commercial exploitation is foreseen.

\section{Conclusion}

In conclusion, the research intends to be an actual contribution in the mathematics didactics field due to innovational exploiting of European and Asian (Singapore's method) learning and teaching approaches combined with the arts. Seen as two sides of the same coin, their combination through "artworks" can enrich both, making young students more familiar with math concepts.

Moreover, the above described involvement of technology during the whole learning and teaching approach can amplify, in an effective way, the skills and creativity development. 


\section{Acknowledgements}

This work is partly funded by the Bulgarian NSF under the research project №DN02/06/15.12.2016 "Concepts and Models for Innovation Ecosystems of Digital Cultural Assets," Research task "Research, adaptation and application of tools for context-dependent use of digital cultural resources by digital culture ecosystems (for training purposes)."

\section{References}

Brousseau, G. (2002). Theory of didactical Situations in Mathematics. New York: Kluwer Academic Publishers.

Clements, D. H. (1999). “Concrete” manipulatives, concrete ideas. Contemporary Issues in Early Childhood, 1(1), 56-57.

ERT. (2009). Mathematics, Science \&Technology Education Report. OECD. Retrieved September 26, 2016, from http://www.ert.eu/sites/default/files/MST\%20Report\%20FINAL.pdf

Gombrich, E.H. (2006). The Story of Art, Perfection Learning Corporation.

Gu, L., Huang, R., \& Marton, F. (2004). Teaching with variation: a Chinese way of promoting effective mathematics learning. In L. Fan, N.-Y. Wong, J. Cai, \& S. Li, How Chinese learn mathematics: Perspectives from insiders (pp. 309-347). Singapore: World Scientific.

Lamb, E. (2012). Bridging the Gap Between Math and Art. Retrieved March 13, 2017, from Scientific American: http://www.scientificamerican.com/article/bridging-the-gap/

Maletic, V. (1987). Body Space Expression: the development of Rudolf Laban's movement and dance concepts. Berlin: Walter de Gruyter \& Co.

Mullis, I. Et al. (2012). TIMSS 2011 International Results in Mathematics. Chestnut Hill, MA, USA: TIMSS \& PIRLS International Study Center, Lynch School of Education, Boston College and International Association for the Evaluation of Educational Achievement (IEA) IEA Secretariat Amsterdam, the Netherland. Retrieved March 10, 2017, from http://timss.bc.edu/timss2011/international-results-mathematics.html

OECD. (2014). PISA 2012 Results in Focus: What 15-year-olds know and what they can do with what they know. OECD. Retrieved March 13, 2017, from https://www.oecd.org/pisa/keyfindings/pisa-2012-results-overview.pdf

Schwartz, K. (2015). How Integrating Arts into Other Subjects Makes Learning Come Alive. Retrieved March 10, 2017, from KQED: http://ww2.kqed.org/mindshift/2015/01/13/how-integrating-arts-into-other-subjects-makes-learning-come-alive/

Senka, G., Plota, S., Monova-Zheleva, M., Zhelev, Y., D., L., \& Paneva-Marinova, D. (2016). Technology-enhanced Teaching of Exact Science through Art. Cultural heritage - conservation, presentation and digitization, 2, pp. 75-79. Veliko Tarnovo.

Zheleva, M., \& Tramonti, M. (2015). Use of the Virtual World for Educational Purposes. Electronic Journal for Computer Science and Communications, 4(2), 106-125. 